\title{
The Welfare Cost of Business Cycles with Heterogeneous Trading Technologies
}

YiLi Chien

\begin{abstract}
The author investigates the welfare cost of business cycles in an economy where households have heterogeneous trading technologies. In an economy with aggregate risk, the different portfolio choices induced by heterogeneous trading technologies lead to a larger consumption inequality in equilibrium, while this source of inequality vanishes in an economy without business cycles. Put simply, the heterogeneity in trading technologies amplifies the effect of aggregate output fluctuation on consumption inequality. The welfare cost of business cycles is, therefore, larger in such an economy. In the benchmark economy with a reasonably low risk aversion rate, the business cycle cost is 6.49 percent perperiod consumption for an average household when the model is calibrated to match the risk premium. (JEL C68, D61, D14, E32, G11, G12)
\end{abstract}

Federal Reserve Bank of St. Louis Review, First Quarter 2015, 97(1), pp. 67-85.

n a calibrated representative agent model, Lucas (1987) shows a very insignificant welfare gain from the elimination of business cycles. His work suggests that the benefits of stabilizing the cyclical fluctuations in an economy are very limited. Hence, studying the business cycle might not be the top priority in macroeconomics. More recently, Lucas (2003) has argued that most macroeconomics models still fail to generate a sizable welfare cost associated with business cycles.

In this article, I investigate the welfare cost of business cycles in an economy where households have heterogeneous trading technologies. In contrast to most research in the incomplete market literature, the menu of assets available in this economy is quite rich. Moreover, households in this model have heterogeneous abilities to access the menu of assets available on the market. My article distinguishes between passive traders, who hold fixed portfolios of stocks and bonds, and active traders, who frequently adjust their portfolios in response to changes in investment opportunities.

The welfare cost of business cycles is defined as the average welfare difference between two economies: one with and one without aggregate output fluctuations. Given the heterogeneous agent economy, the average welfare is computed by taking the expectation not only

YiLi Chien is a senior economist at the Federal Reserve Bank of St. Louis.

() 2015, The Federal Reserve Bank of St. Louis. The views expressed in this article are those of the author(s) and do not necessarily reflect the views of the Federal Reserve System, the Board of Governors, or the regional Federal Reserve Banks. Articles may be reprinted, reproduced, published, distributed, displayed, and transmitted in their entirety if copyright notice, author name(s), and full citation are included. Abstracts, synopses, and other derivative works may be made only with prior written permission of the Federal Reserve Bank of St. Louis. 
over time but also across all idiosyncratic features of the population. In other words, this welfare measure acts as if people were asked ex ante which economy they would like to be born in. Hence, the measure of business cycles can be thought of as the amount of consumption compensation newborns should receive such that they are indifferent in their expected utilities between the two economies.

In the equilibrium of the calibrated economy, heterogeneous trading technologies result in a clear difference between active traders and passive traders with respect to their portfolio choices. In response to the high risk premium, households with more sophisticated trading technologies take greater aggregate risks by holding a large fraction of equities in their portfolios. They also optimally adjust their portfolios in response to changes in investment opportunities. On the other hand, households with less sophisticated trading technologies take a more cautious approach. On average, they bear less aggregate risk by holding a smaller fraction of equities in their portfolios and do not actively respond to changes in market conditions. The active traders ultimately earn a high rate of return on their portfolios, accumulating more wealth and enjoying a high level of consumption, while the passive investors earn a low return on their portfolios, thereby acquiring relatively low levels of wealth and consuming less. Hence, heterogeneous trading technologies induce more consumption inequality in this economy. Most importantly, the higher consumption inequality across the population leads to lower welfare under my welfare measure.

Clearly, the source of consumption inequality depends heavily on the risk premium level and the variation in the market price of risk; both are linked tightly to business cycle fluctuations. A reduction of aggregate output volatility helps reduce not only the size but also the time variation of the risk premium. This reduction downplays the role of portfolio choice and, hence, reduces consumption inequality and improves welfare in the economy. Without aggregate risk, the inequality in consumption caused by the heterogeneous trading technologies disappears since the composition and timing of portfolio choice no longer affect the rate of return. In short, all assets are risk free and offer exactly the same rate of return. A more sophisticated trading technology does not offer any advantage in an environment without aggregate risk.

I conjecture that heterogeneous trading technologies may contribute to the welfare cost of business cycles. In an economy with aggregate risk, the different portfolio choices across households lead to a larger consumption inequality in equilibrium, while this source of inequality vanishes in an economy without business cycles. In short, the consumption inequality caused by aggregate output fluctuation is amplified by the heterogeneous trading technologies. The welfare cost of business cycles is, therefore, larger in such an economy.

This article uses the modified macroeconomics model developed by Chien, Cole, and Lustig (2011) to evaluate the conjecture quantitatively. Their model incorporates heterogeneous trading technologies into an otherwise standard macroeconomics model. In my use of the model, the heterogeneity in trading technologies is calibrated to match the high risk premiums seen in the historical U.S. data. The welfare cost is measured by the average percentage of per-period consumption compensation received by a newly born household in an economy without business cycles, such that this household is indifferent to an environment with aggregate fluctuations. I find that the welfare gain from the elimination of business cycles is large, 
with a reasonably low risk aversion coefficient. In my benchmark case where the risk aversion coefficient is 4 , the business cycle costs each household in my economy 6.49 percent of perperiod consumption. The welfare cost is significantly larger than that calculated by Lucas (1987).

I also compute the case in which all households are active traders and are endowed with the same sophisticated trading technologies. Given the parameter values in my benchmark calibration, the results show a low risk premium and a much smaller cost of business cycles. The importance of this computational exercise is twofold. First, it shows how an inferior investment technology among some of the investors influences the patterns of return in asset markets. If all households make no investment mistakes, the asset pricing result is dampened compared with that in my benchmark economy. Second, it demonstrates a large welfare loss resulting from poor investment strategies. This exercise shows that the welfare cost of business cycles is much smaller if no household makes investment errors. The heterogeneous trading technologies contribute significantly and mostly to the welfare cost number in my benchmark economy.

The assumption of heterogeneous trading technologies is critical to my results. The question thus arises: How realistic is the assumption of heterogeneous trading technologies? The answer can be found in empirical studies and data that have shown a high amount of heterogeneity in household portfolio choices. Different households behave as if they had access to different menus of tradable assets. In the United States, a majority of households do not invest directly in equity despite the sizable historical equity premiums. Even for those who participate in the equity market, most do not frequently adjust the composition of their portfolios, regardless of the large countercyclical variation of Sharpe ratios (SRs) in the equity market. Put simply, they miss the market timing. However, a small fraction of households hold a large share of stock and constantly change their equity position in response to the high variable-risk premiums. Therefore, these households end up richer but have more exposure to aggregate risk. Parker and Vissing-Jorgensen (2009) show that the consumption of the richest 10 percent of U.S. households is five times more exposed to aggregate risk than that of average households.

This article is closely related to the body of literature in which the distribution effects on consumption inequality might justify a large welfare cost of business cycles. Krusell and Smith (1999) propose the idea that business cycles might worsen the consumption inequality across the population while the impact on average households is insignificant. The higher cost of business cycles is due to the distributional impact of consumption among the rich and poor. Evidently, the distributional impact is missing in a representative agent economy. Krusell et al. (2009) use an incomplete market model calibrated to the wealth distribution in the United States to evaluate the welfare cost of business cycles. Using the same parameter for risk aversion as in Lucas (1987), they find the welfare cost is approximately 0.1 percent of household consumption. Although the welfare cost is one magnitude larger than that calculated by Lucas, it is still negligible in an economic sense. Storesletten, Telmer, and Yaron (2001) consider the welfare cost of business cycles in an environment with countercyclical variations in idiosyncratic shock. A more volatile idiosyncratic income risk during recessions can amplify the cost of aggregate risk in individual consumption and leads to a higher distributional impact. Although the welfare cost of business cycles is still insignificant, the cost increases rapidly as 
the risk aversion coefficient increases. Krebs (2007) extends the concept of idiosyncratic labor income shock by adding a permanent job displacement risk. The risk of job displacement is assumed to be closely associated with the business cycle. He finds a sizable cost of business cycles related to the importance of displacement risks.

The central idea of this corpus of literature is to translate a low scale of aggregate risk into a large consumption inequality. I follow this concept, but the large consumption inequality in my model is caused by a novel feature: heterogeneity in trading technologies. Most articles in this literature operate under incomplete market models in which all households can trade only a very limited menu of tradable assets. However, the actual menu of assets that households can trade is quite rich. Instead of assuming a limited set of tradable assets, I introduce a heterogeneous ability to access the menu of assets, motivated by the empirical evidence of heterogeneity in portfolio choices. With heterogeneous trading technologies, households' total incomes differ not only because of their idiosyncratic risk in labor income but also because of the variations in their investment returns resulting from the heterogeneity in trading technologies. In addition, heterogeneous trading technologies affect the return of portfolio choices only in an economy with aggregate risk. Without business cycles, the cost of consumption inequality from different trading technologies disappears. Therefore, the heterogeneity in trading technologies only enlarges the consumption inequality in an economy with aggregate risk and, hence, amplifies the cost of business cycles.

Alvarez and Jermann (2004) demonstrate a close link between the cost of business cycles and risk premiums. Their work offers an alternative and intuitive way to measure the cost of business cycles by using asset pricing data. The cost of business cycles can be considered as the valuation difference between two consumption claims: One pays a constant stream of consumption and the other pays a stochastic stream of consumption. In a representative agent framework, the former claim represents a consumption stream in an economy without aggregate shocks and the latter represents a consumption stream with aggregate shocks. Hence, their work illustrates that, under a representative agent economy, the welfare cost of business cycles can be approximated by the risk premium between an aggregate stochastic consumption claim and a risk-free asset, regardless of the assumptions about utility function. Based on their observation, one can infer that if a model generates a high risk premium, then it might also imply a larger welfare cost of business cycles. My calibrated model produces a realistic result for asset pricing; however, my model's mechanism differs from that in Alvarez and Jermann (2004). The large welfare cost results mainly from the consumption inequality induced by heterogeneous trading technologies, not directly from the variations in aggregate consumption over time.

This article also relates to the fast-growing body of literature on household finance. Campbell (2006) points out that some households might make various mistakes when facing complicated financial decisions. This article evaluates the welfare cost of some of these mistakes. In the model economy, passive traders make two types of mistakes. Households that do not participate in the equity market forgo the large equity premium. Also, those equity investors who do not frequently change their portfolio choices miss the market timing. By comparing the results of two model economies, one with heterogeneous trading technologies 
and the other without heterogeneous trading technologies, I demonstrate that these investment mistakes not only affect the risk premium patterns but also cause a large welfare cost. If all households consist of active traders who do not make any investment mistakes, then the risk premium is low and stable in the calibrated economy. Moreover, the welfare cost of business cycles is almost negligible and similar to the result found by Lucas (1987). This finding emphasizes the importance of the study of household finance because preventing investment mistakes can considerably improve welfare.

The next section describes the environment and trading technologies, followed by a section discussing the calibration of the model. Then the results and sensitivity analyses are presented. The final section offers the conclusion.

\section{MODEL}

The model setup closely follows that in Chien, Cole, and Lustig (2011). The novel feature of their model is the imposition of restrictions on the menu of assets that households are able to trade, which defines the trading technology a household owns. These restrictions are imposed exogenously to capture the observed portfolio behavior of most households.

I refer to households as passive traders if they take their portfolio composition as given and simply choose how much to save or dissave in each period. Other households constantly manage their portfolios in response to changes in the investment opportunity set. I refer to these households as active traders since they optimally adjust the composition of their portfolios every period. Note that the passive traders are completely rational except in their portfolio choice decisions. They fully acknowledge the rate of return on their portfolios and adjust their consumption and saving decisions accordingly. Hence, the results are clearly driven by the only additional novel assumption - heterogeneous trading technologies-in contrast to most research in the incomplete market literature.

\section{Environment}

This endowment economy consists of a continuum of heterogeneous households subject to both idiosyncratic income shocks and aggregate endowment shocks. The total measure of households is normalized to 1 . The heterogeneity across households arises from two assumptions. In the planning period $t=0$, households receive a one-time permanent shock to their trading technologies, while all other characteristics of the households are identical. Starting at period 1, these households also differ in terms of the realization of an idiosyncratic income shock at all subsequent periods. All households start with the same amount of initial wealth and face an identical stochastic process of idiosyncratic income shocks.

In the model, time is discrete, infinite, and indexed by $t=0,1,2, \ldots$. The first period, $t=0$, is the planning period in which financial contracting takes place. I use $z_{t} \in Z$ to denote the aggregate shock in period $t$ and $\eta_{t} \in N$ to denote the idiosyncratic shock in period $t$. The variable $z^{t}$ denotes the history of aggregate shocks, and similarly $\eta^{t}$ denotes the history of idiosyncratic shocks for a household. The idiosyncratic events $\eta$ are i.i.d. across households with the 
mean normalized to 1 . I use $\pi\left(z^{t}, \eta^{t}\right)$ to denote the unconditional probability of state $\left(z^{t}, \eta^{t}\right)$ being realized. The events are first-order Markov, and I assume that

$$
\pi\left(z^{t+1}, \eta^{t+1} \mid z^{t}, \eta^{t}\right)=\pi\left(z_{t+1} \mid z_{t}\right) \pi\left(\eta_{t+1} \mid \eta_{t}\right)
$$

Note that the probability of idiosyncratic events does not depend on the realization of aggregate shocks. As I show later, this article does not consider the countercyclical variation of idiosyncratic risk. I introduce some additional notation: $z^{t+1}>z^{t}$ or $\eta^{t+1}>\eta^{t}$ denotes that the left node is a successor node to the right node. I use $\left\{z^{\tau}>z^{t}\right\}$ to denote the set of successor aggregate histories from $z^{t}$ onward.

There is a single nondurable good available for consumption in each period, and its aggregate supply is denoted by $Y_{t}\left(z^{t}\right)$, which evolves according to

$$
Y_{t}\left(z^{t}\right)=\exp \left\{z_{t}\right\} Y\left(z^{t-1}\right)
$$

with $Y\left(z^{0}\right)=1$. This endowment good comes in two forms. The first part is nondiversifiable income subject to idiosyncratic risk and is denoted by $\gamma Y\left(z^{t}\right) \eta^{t}$; hence $\gamma$ is the share of income that is nondiversifiable. Nondiversifiable income cannot be traded in financial markets and may be considered labor income. The second part of the endowment good is diversifiable income, which is not subject to idiosyncratic shocks, and is denoted by $(1-\gamma) Y_{t}\left(z^{t}\right)$.

All households are infinitely lived, and rank stochastic consumption streams according to the following utility function:

$$
U(\{c\})=\sum_{t \geq 1,\left(z^{t}, \eta^{t}\right)}^{\infty} \beta^{t} \pi\left(z^{t}, \eta^{t}\right) \frac{c_{t}\left(z^{t}, \eta^{t}\right)^{1-\alpha}}{1-\alpha},
$$

where $\alpha>0$ denotes the coefficient of relative risk aversion and $c_{t}\left(z^{t}, \eta^{t}\right)$ denotes the household's consumption in state $\left(z^{t}, \eta^{t}\right)$.

\section{Assets Traded}

Three assets are available in this economy: equity, bond, and contingent claims on aggregate shocks. All of these assets are claims on diversifiable income. The actual menu of assets that a household can trade depends on its trading technology. However, this is still an incomplete market economy because there is no state-contingent claim on idiosyncratic shocks.

Following Abel (1999), I simply consider equity as a leveraged claim on aggregate diversifiable income $\left((1-\gamma) Y_{t}\left(z^{t}\right)\right)$. The leverage ratio is assumed to be constant over time and denoted by $\psi$. Let $B_{t}\left(z^{t}\right)$ denote the supply of a one-period risk-free bond in period $t$ and $R_{t, t-1}^{f}\left(z^{t-1}\right)$ denote the risk-free rate between periods $t-1$ and $t$ given the aggregate history $z^{t-1}$. With a constant leverage ratio, the total supply of $B_{t}\left(z^{t}\right)$ has to be adjusted such that

$$
B_{t}\left(z^{t}\right)=\psi\left[W_{t}\left(z^{t}\right)-B_{t}\left(z^{t}\right)\right]
$$


where $W_{t}\left(z^{t}\right)$ is the price of a claim on aggregate diversifiable income. Because the aggregate diversified income can be decomposed into the interest payment to bond holders and the dividend payment to shareholders, the dividend payment, $D_{t}\left(z^{t}\right)$, is denoted by

$$
D_{t}\left(z^{t}\right)=(1-\gamma) Y_{t}\left(z^{t}\right)-R_{t, t-1}^{f}\left(z^{t-1}\right) B_{t-1}\left(z^{t-1}\right)+B_{t}\left(z^{t}\right) .
$$

Traders who invest a fraction $\psi /(1+\psi)$ of their wealth in bonds and the rest in equity hold the market portfolio. I denote the price of equity (a claim on dividend payment $D_{t}\left(z^{t}\right)$ ) by $V_{t}\left(z^{t}\right)$.

The third available asset is the aggregate state-contingent claims. I denote the price of a unit claim on the final good in aggregate state $z^{t+1}$ acquired in aggregate state $z^{t}$ by $Q_{t}\left(z_{t+1}, z^{t}\right)$.

I consider a household entering the period with a net financial wealth $\hat{a}_{t}\left(z^{t}, \eta^{t}\right)$. This household buys securities in financial markets (state-contingent claims $a_{t}\left(z^{t+1}, \eta^{t+1}\right)$, risk-free bonds $b_{t}\left(z^{t}, \eta^{t}\right)$, and equity shares $\left.s_{t}^{D}\left(z^{t}, \eta^{t}\right)\right)$ and with consumption $c_{t}\left(z^{t}, \eta^{t}\right)$ in the goods markets subject to the following one-period budget constraint:

$$
\begin{aligned}
& \sum_{z^{t+1} \succ z^{t}, \eta^{t+1} \succ \eta^{t}} Q_{t}\left(z_{t+1}, z^{t}\right) a_{t}\left(z^{t+1}, \eta^{t+1}\right) \pi\left(\eta_{t+1} \mid \eta_{t}\right)+s_{t}^{D}\left(z^{t}, \eta^{t}\right) V_{t}\left(z^{t}\right)+b_{t}\left(z^{t}, \eta^{t}\right)+c_{t}\left(z^{t}, \eta^{t}\right) \\
& \leq \hat{a}_{t}\left(z^{t}, \eta^{t}\right)+\gamma Y_{t}\left(z^{t}\right) \eta_{t}, \forall z^{t}, \eta^{t}
\end{aligned}
$$

where $\hat{a}_{t}\left(z^{t}, \eta^{t}\right)$, the agent's net financial wealth in state $\left(z^{t}, \eta^{t}\right)$, is given by the payoffs of his or her state-contingent claim acquired last period, the payoffs from his or her equity position, and the risk-free bond payoffs:

$$
\hat{a}_{t}\left(z^{t}, \eta^{t}\right)=a_{t-1}\left(z^{t}, \eta^{t}\right)+s_{t}^{D}\left(z^{t-1}, \eta^{t-1}\right)\left[D_{t}\left(z^{t}\right)+V_{t}\left(z^{t}\right)\right]+R_{t, t-1}^{f}\left(z^{t-1}\right) b_{t-1}\left(z^{t-1}\right) .
$$

\section{Trading Technology}

There are two main classes of traders: active traders and passive traders. Active traders are able to trade state-contingent claims on aggregate shocks. They change their portfolio composition of equity and bonds optimally every period in response to the variations of statecontingent prices. These active traders make no mistakes in their investment choices. In contrast, passive traders cannot trade state-contingent claims, and their portfolio choice is limited by an exogenously assigned and fixed target $\varpi$ for the equity share. I refer to these traders as passive precisely because of their inelastic response to the changes in investment opportunities. These passive traders potentially make two kinds of investment mistakes. First, they miss the market timing if the volatility of the market price of risk is not constant in the equilibrium. Second, for those passive traders who hold small or zero fractions of equity in their portfolios, they relinquish the risk premiums. The welfare cost of their mistakes may be large in the equilibrium, exhibiting a large risk premium and a volatile SR in equity.

In addition, households face exogenous limits on their net asset positions, or solvency constraints, 


$$
\hat{a}_{t}\left(z^{t}, \eta^{t}\right) \geq 0
$$

Equation (2) reflects the fact that traders cannot borrow against their future nondiversifiable income.

\section{Measurability Restrictions}

The portfolio restrictions implied by the different trading technologies can be translated into restrictions on the evolution of net wealth. These restrictions on net wealth are called measurability constraints. Measurability constraints allow us to derive an aggregation pricing kernel and to avoid searching for all the equilibrium prices that clear all markets (see Chien, Cole, and Lustig, 2011, for a detailed discussion). Below, I list the measurability restrictions for each type of trader.

Active Trader. Since idiosyncratic shocks are not spanned for the active traders, their net wealth needs to satisfy

$$
\hat{a}_{t}\left(z^{t},\left[\eta_{t}, \eta^{t-1}\right]\right)=\hat{a}_{t}\left(z^{t},\left[\tilde{\eta}_{t}, \eta^{t-1}\right]\right)
$$

for all $t$ and $\eta_{t}, \tilde{\eta}_{t} \in N$. These constraints guarantee that the net asset positions are the same across all realizations of idiosyncratic shocks in each period since the active traders are not allowed to trade state-contingent claims on idiosyncratic shocks.

Passive Trader. Passive traders who hold a fixed fraction $\varpi$ in levered equity and $1-\varpi$ in noncontingent bonds in their portfolio earn a portfolio return:

$$
R_{t}^{p}\left(\varpi, z^{t}\right)=\varpi R_{t, t-1}^{d}\left(z^{t}\right)+(1-\varpi) R_{t, t-1}^{f}\left(z^{t-1}\right)
$$

where $R_{t, t-1}^{d}\left(z^{t}\right)$ denotes the equity return between periods $t$ and $t-1$ given the realization of history state $z^{t}$. Hence, their net financial wealth satisfies this measurability restriction:

$$
\frac{\hat{a}_{t}\left(\left[z_{t}, z^{t-1}\right],\left[\eta_{t}, \eta^{t-1}\right]\right)}{R_{t}^{p}\left(\varpi,\left[z_{t}, z^{t-1}\right]\right)}=\frac{\hat{a}_{t}\left(\left[\tilde{z}_{t}, z^{t-1}\right],\left[\tilde{\eta}_{t}, \eta^{t-1}\right]\right)}{R_{t}^{p}\left(\varpi,\left[\tilde{z}_{t}, z^{t-1}\right]\right)},
$$

for all $t, z_{t}, \tilde{z}_{t} \in Z$, and $\eta_{t}, \tilde{\eta}_{t} \in N$. This restriction is straightforward to understand: The net asset holding at the beginning of period $t, \hat{a}_{t}$, divided by the portfolio return between periods $t$ and $t-1, R_{t}^{p}$, state by state, should all be equal to the net wealth at the end of period $t-1$. Two fixed portfolio choices are worth mentioning here. First, if $\varpi=1 /(1+\psi)$, then this trader holds the market in each period and earns the return on a claim on aggregate diversifiable income. Second, some passive traders do not participate in the equity market and hold only risk-free assets. I call them nonparticipants, who can be thought of as having a zero equity target share, $\varpi=0$.

\section{Competitive Equilibrium}

The competitive equilibrium for this economy is defined in a standard manner. It consists of a list of bond, equity, and state-contingent claims holdings; a consumption allocation; and 
a list of bond, equity, and state-contingent prices such that (i) given these prices, a trader's asset and consumption choices maximize his or her expected utility subject to the budget constraints, the solvency constraints, and the measurability constraints, and (ii) all asset markets clear.

\section{CALIBRATION}

This section discusses the calibration of the parameters, the endowment processes, and the composition of trader pools. The next section uses a calibrated version of the model to evaluate the welfare effect of eliminating business cycles. To compute the equilibrium of this economy, I follow the algorithm described by Chien, Cole, and Lustig (2011), who use truncated aggregate histories as state variables. I track the lagged aggregate histories for up to seven periods.

\section{Preferences and Endowments}

Lucas (2003) suggested that a reasonable risk aversion coefficient should lie between 1 and 4. My benchmark calibration set the coefficient of relative risk aversion $\alpha$ to 4 . To check the robustness of my results with respect to the choice of risk aversion rate, I conduct a sensitivity analysis as detailed in the "Sensitivity Analysis" subsection. The model is calibrated to annual data. The time discount factor $\beta$ is set to 0.95 . Following Chien, Cole, and Lustig (2012), the fraction of nondiversifiable output is set to 90 percent, which is also close to the value in Mendoza, Quadrini, and Ríos-Rull (2009): 88.75 percent.

The process of aggregate output is calibrated to match the aggregate consumption growth moments from Alvarez and Jermann (2001) and Mehra and Prescott (1985). The average consumption growth rate is 1.83 percent and the standard deviation (SD) is 3.15 percent. The autocorrelation of consumption growth is -0.14 . Expansions are more frequent than recessions: Seventy-three percent of realizations are states of high aggregate consumption growth. I calibrate the labor income process as in Storesletten, Telmer, and Yaron $(2004,2007)$, except that I eliminate the countercyclical variation of labor income risk. The variance of labor income risk is constant in this model. An invariant labor income risk setup highlights the role of the new feature (heterogeneous trading technologies) considered in this article. The main driving force of my result is the heterogeneity in trading technology, not the countercyclical variation of labor income risk. The Markov process for $\log \eta$ has an SD of 0.71 , and the autocorrelation is 0.89 . I use a four-state discretization for both aggregate and idiosyncratic risk. The elements of the process for $\log \eta$ are 0.38 and 1.61 for low and high shocks, respectively.

The equity in my model is simply a leveraged claim on diversifiable income. In the Financial Accounts of the United States (formerly the Flow of Funds Accounts tables), the ratio of corporate debt to net worth is around 0.65 , suggesting a leverage parameter $\psi$ of 2 . However, Cecchetti, Lam, and Mark (1990) report that the SR of the growth rate of dividends is at least 3.6 times that of aggregate consumption, suggesting that the appropriate leverage level is over 3. Following Abel (1999) and Bansal and Yaron (2004), I choose to set the leverage parameter $\psi$ to 3 . 


\section{Composition of Trader Pools and Equity Target Share}

I set the fraction of nonparticipants at 50 percent based on the fact that 51.1 percent of households reported owning stocks directly or indirectly in a recent Survey of Consumer Finances. To match the large equity premium (7.53 percent) measured in postwar U.S. data, a relatively small fraction of active traders needs to bear the large amount of residual aggregate risks created by nonparticipants. Hence, I set the share of active traders at 10 percent and the share of passive equity traders at 40 percent.

Among those households that hold equity, I am not able to distinguish between active traders and passive equity traders in the data. It is difficult to calibrate the target equity share of passive equity traders, since I do not know who they are. However, empirical studies have shown that rich households tend to be more sophisticated traders. Therefore, I consider the richest 10 percent of households to be active traders and the poorest 50 percent of households to be nonparticipants. The target equity share of passive equity traders is therefore calibrated to match the average fraction of equity among those households that possess a percentile of wealth between 50 percent and 90 percent (the middle wealthy). According to the data from the Survey of Consumer Finances, the average equity share among these middle wealthy households is 24.2 percent. I, therefore, set the equity target share of the passive equity traders at 24 percent. This calibration also reflects the observation that the rich tend to hold a higher fraction of equity than the poor.

\section{QUANTITATIVE RESULTS}

I consider two cases in the quantitative exercise. The first case is the benchmark economy, where the parameters are calibrated as described earlier. The second case I consider is another economy with no heterogeneity in trading technologies. All households are able to access all assets available on the market with no restrictions. Table 1 reports moments of asset prices in both of the economies considered. These results are generated by simulating data from a model with 12,000 agents for 10,000 periods. Panels A and B report results for the benchmark economy and the economy with no heterogeneity in trading technologies, respectively.

\section{Asset Prices}

The "Asset pricing" section of Table 1 shows the maximum unconditional SR, or market price of risk $\left(\frac{\sigma(m)}{E(m)}\right)$, the SD of the maximum SR $\left(\operatorname{Std}\left(\frac{\sigma_{t}(m)}{E_{t}(m)}\right)\right)$, the equity risk premium $E\left(R_{t+1, t}^{D}-R_{t+1, t}^{f}\right)$, the SD of excess returns $\sigma\left(R_{t+1, t}^{D}-R_{t+1, t}^{f}\right)$, the SR on equity, the mean riskfree rate $E\left(R_{t+1, t}^{f}\right)$, and the SD of the risk-free rate $\sigma\left(R_{t+1, t}^{f}\right)$.

Benchmark Economy. In the benchmark economy, the maximum SR is 0.37 and the $\mathrm{SD}$ of the maximum SR is 4.04 percent. The equity premium is 7.54 percent and the SR on equity is 0.37 . The average risk-free rate is 1.91 percent and its volatility is 2.27 percent. Clearly, the benchmark economy generates several key features of asset pricing observed in the data, 


\section{Table 1}

\section{Results of Benchmark and NHT Economy}

\begin{tabular}{|c|c|c|}
\hline & $\begin{array}{c}\text { Panel A: } \\
\text { Benchmark economy }\end{array}$ & $\begin{array}{l}\text { Panel B: } \\
\text { NHT economy }\end{array}$ \\
\hline Active traders (\%) & 10 & 100 \\
\hline Passive equity traders (\%) & 40 & 0 \\
\hline Nonparticipants (\%) & 50 & 0 \\
\hline \multicolumn{3}{|l|}{ Asset pricing } \\
\hline Market price of risk: $\frac{\sigma(m)}{E(m)}$ & 0.3739 & 0.1528 \\
\hline SD of market price of risk: $S t d\left[\frac{\sigma_{t}(m)}{E_{t}(m)}\right](\%)$ & 4.0440 & 1.0106 \\
\hline Equity risk premium: $E\left(R_{t+1, t}^{D}-R_{t+1, t}^{f}\right)(\%)$ & 7.5368 & 3.0077 \\
\hline SD of equity premium: $\sigma\left(R_{t+1, t}^{D}-R_{t+1, t}^{f}\right)(\%)$ & 20.3867 & 19.7216 \\
\hline SR & 0.3697 & 0.1525 \\
\hline Risk-free rate: $E\left(R_{t+1, t}^{f}\right)(\%)$ & 1.9141 & 3.0900 \\
\hline SD of risk-free rate: $\sigma\left(R_{t+1, t}^{f}\right)(\%)$ & 2.2729 & 2.2539 \\
\hline \multicolumn{3}{|l|}{ Approximation } \\
\hline$R^{2}$ & $>0.9995$ & $>0.9999$ \\
\hline \multicolumn{3}{|l|}{ Welfare cost } \\
\hline Welfare cost of business cycle (\%) & 6.49 & 1.45 \\
\hline
\end{tabular}

such as high equity premiums, a low and stable risk-free interest rate, and a relatively volatile SR. ${ }^{1}$

The large fraction of nonparticipant traders is critical for the results with high risk premiums. Those households that hold only risk-free assets do not take on any aggregate risk since their portfolio return is independent of the realization of aggregate shocks. Additionally, passive equity traders take on only a limited amount of aggregate risk because of their relatively low and constant target equity share. Therefore, a large amount of aggregate risk has to be absorbed by a small fraction of active traders. In equilibrium, a high risk premium is necessary so that active traders are willing to bear these extra aggregate risks. The key mechanism is to concentrate the aggregate risk in a small fraction of the population.

No Heterogeneous Trading Economy. In an economy where all households are active traders, the asset pricing results are dampened. Compared with the benchmark case, the maxi- 
mum SR is only 0.15 and the SD of the maximum SR decreases to 1.01 percent. The equity premium decreases to 3.01 percent and the SR on equity is only 0.15 . The average risk-free rate increases to 3.09 percent and its volatility remains roughly the same, 2.25 percent. The heterogeneity in trading technologies considerably affects the patterns of asset pricing results. The reason for the low equity premium is clear: The aggregate risk is equally borne by all households, and there is no concentration of risk in a small fraction of households as in the benchmark economy.

Approximation. In general, the prices of state-contingent claims depend on the entire aggregate history, which is intractable in computation. Following Chien, Cole, and Lustig (2011), I use truncated aggregate histories as state variables to forecast state-contingent prices. To show the accuracy of my approximation, I report the implied $R$-squared value from a linear regression of the actual realization of state-contingent prices on the predicted state-contingent prices, which are based on the truncated aggregate histories. This measure of precision is close to that of Krusell and Smith (1998). As shown in Table 1, the $R$-squared value for this regression is higher than 0.9995 in the benchmark case and higher than 0.9999 in the case without heterogeneous trading technologies. This result shows that the approximation is accurate and comparable to others reported in the literature for models with heterogeneous agents and incomplete markets.

\section{Welfare Costs of Business Cycles}

The welfare cost of eliminating business cycles is defined as the average welfare difference between two economies: one with aggregate shocks and the other without aggregate shocks. Given the fact that households are heterogeneous in terms of their wealth, income shocks, and trading technologies in the long-run equilibrium, the average welfare of one economy is computed by taking the expectation across all idiosyncratic features of the population. In addition, I measure the average welfare gap between the two economies by calculating the percentage of per-period consumption. Therefore, the welfare cost is defined as the expected percentage of consumption compensation for a household in an economy without business cycles, so that this household is indifferent to joining the benchmark economy. The welfare cost is reported at the bottom of Table 1 .

Benchmark Economy. In the benchmark economy, the welfare cost of business cycles is 6.49 percent. This number means that the average household in the benchmark economy is willing to relinquish up to 6.49 percent of its per-period consumption to be in the other economy without aggregate uncertainty, all else being equal. The welfare cost is much larger than most of the findings in the body of literature. This result demonstrates that heterogeneous trading technologies play an important role not only in the patterns of asset pricing but also in the distributional effects of consumption. In the benchmark economy, the households with better trading technologies earn a higher return on their wealth, while the households with less sophisticated trading technologies earn a lower return. This phenomenon generates a distributional impact on consumption and eventually widens the welfare gap across households. However, the welfare inequality caused by heterogeneous trading technologies vanishes in an economy without business cycles. The reason for this is quite simple: Since all assets are risk 
free, the portfolio choice between equity and risk-free bonds does not affect the return on the portfolios. There is no investment advantage for a household that has an advanced trading technology. The returns on wealth between active traders and passive traders are identical in an environment without aggregate risk.

As discussed earlier, the large welfare cost is mainly driven by the consumption inequality caused by heterogeneous trading technologies. A reasonable question is "To what extent does the consumption inequality in our model compare with that in the data?" This is especially important since the model is not calibrated to match the consumption dispersion observed in the data. Krueger and Perri (2006) reported a narrow variation of the Gini index in U.S. consumption inequality ranging from 0.23 to 0.26 between 1980 and 2003. The simulated data of the benchmark model generate a Gini index of 0.248 , which is in the range of the reported data even though the consumption inequality is not targeted in calibration. This finding enhances the confidence of the welfare calculation.

No Heterogeneous Trading Economy. In my second exercise, where all households are active traders, the welfare cost is only 1.45 percent. $^{2}$ This low welfare cost is consistent with the findings in the literature on the cost of business cycles. This result suggests that the welfare cost of business cycles is less significant in an environment where all agents have sophisticated trading technologies and make no investment mistakes. This outcome can easily be understood: Because all households have the same trading technologies, there is no heterogeneity in portfolio choice. The income and consumption inequality are greatly reduced in this case. The aggregate risk no longer amplifies the distributional impact on consumption, so the welfare cost of business decreases considerably.

The amount of reduction in the welfare cost of business cycles can be seen as the average welfare gain from preventing the investment mistakes made by passive traders in my model. Clearly, the results show that the average welfare loss resulting from these investment errors is large: 5.04 percent of per-period consumption (the welfare cost difference between the benchmark economy and the economy with no heterogeneity in trading technologies). This number implies that the welfare cost of inferior trading technologies is sizable. My findings also shed light on the importance of understanding the investment mistakes made by passive traders, since avoiding them can improve the average welfare of the society.

\section{Sensitivity Analysis}

Risk Aversion Coefficient. The benchmark calibration sets the risk aversion coefficient to 4 . Although my choice of risk aversion is in the range considered in many macroeconomics models, it is different from the choice made by Lucas (1987), who uses a log utility. More importantly, the welfare cost of business cycles might be sensitive to the risk aversion rate. Here, I investigate the sensitivity of the results to changes in the risk aversion coefficient by conducting two sensitivity analyses with respect to changes in the risk aversion rate. In each analysis, I vary the risk aversion coefficient from 3 to 1 .

The first analysis considers only changes in the risk aversion rate while keeping all other parameters unchanged. Table 2 reports the results of my first analysis. The decrease in the risk aversion rate lowers the risk premium as well as the welfare cost. The risk premium drops 
Table 2

\section{Results of Sensitivity Analysis 1}

\begin{tabular}{|c|c|c|c|}
\hline & Panel A & Panel B & Panel C \\
\hline Risk aversion rate $(\alpha)$ & 3 & 2 & 1 \\
\hline Active traders (\%) & 10 & 10 & 10 \\
\hline Passive equity traders (\%) & 40 & 40 & 40 \\
\hline Nonparticipants (\%) & 50 & 50 & 50 \\
\hline \multicolumn{4}{|l|}{ Asset pricing } \\
\hline Market price of risk: $\frac{\sigma(m)}{E(m)}$ & 0.2856 & 0.1868 & 0.0872 \\
\hline SD of market price of risk: $S t d\left[\frac{\sigma_{t}(m)}{E_{t}(m)}\right](\%)$ & 3.2615 & 2.1882 & 1.0307 \\
\hline Equity premium: $E\left(R_{t+1, t}^{D}-R_{t+1, t}^{f}\right)(\%)$ & 5.1849 & 3.0434 & 1.2799 \\
\hline SD of equity premium: $\sigma\left(R_{t+1, t}^{D}-R_{t+1, t}^{f}\right)(\%)$ & 18.3498 & 16.4103 & 14.6313 \\
\hline SR & 0.2826 & 0.1855 & 0.0875 \\
\hline Risk-free rate: $E\left(R_{t+1, t}^{f}\right)(\%)$ & 2.8186 & 3.8275 & 4.8322 \\
\hline SD of risk-free rate: $\sigma\left(R_{t+1, t}^{f}\right)(\%)$ & 1.6744 & 1.0946 & 0.5360 \\
\hline \multicolumn{4}{|l|}{ Approximation } \\
\hline$R^{2}$ & 0.9997 & 0.9997 & 0.9998 \\
\hline \multicolumn{4}{|l|}{ Welfare cost } \\
\hline Welfare cost of business cycle (\%) & 5.27 & 4.22 & 0.6 \\
\hline
\end{tabular}

substantially, from 5.18 percent with a risk aversion coefficient of 3 to 1.28 percent in the log utility case. In addition, the welfare cost of eliminating business cycles decreases in a nonlinear pattern. With a risk aversion rate of 3 or 2 , the welfare costs are still very significant: 5.27 percent and 4.22 percent, respectively. However, the costs are sharply reduced-to 0.6 percentwhen I consider the case of log utility. This analysis demonstrates a close relationship between the risk premium and the welfare cost of business cycles. This is not surprising, because the welfare cost of business cycles in my article depends critically on the magnitude of consumption dispersion, which is based on the return difference between equity and risk-free bonds. As the risk premium decreases, the heterogeneity in wealth returns is reduced along with the welfare cost.

The first analysis indicates that when households become less risk-averse, the model misses the calibration target, the equity premium, by a wide margin. Therefore, I conduct a second 


\section{Table 3}

\section{Results of Sensitivity Analysis 2}

\begin{tabular}{|c|c|c|c|}
\hline & Panel A & Panel B & Panel C \\
\hline Risk aversion rate $(\alpha)$ & 3 & 2 & 1 \\
\hline Active traders (\%) & 3 & 1 & 1 \\
\hline Passive equity traders (\%) & 47 & 49 & 49 \\
\hline Nonparticipants (\%) & 50 & 50 & 50 \\
\hline \multicolumn{4}{|l|}{ Asset pricing } \\
\hline Market price of risk: $\frac{\sigma(m)}{E(m)}$ & 0.3957 & 0.3461 & 0.2238 \\
\hline SD of market price of risk: $\operatorname{Std}\left[\frac{\sigma_{t}(m)}{E_{t}(m)}\right](\%)$ & 7.5114 & 9.6565 & 9.5149 \\
\hline Equity premium: $E\left(R_{t+1, t}^{D}-R_{t+1, t}^{f}\right)(\%)$ & 7.3828 & 5.7938 & 3.0422 \\
\hline SD of equity premium: $\sigma\left(R_{t+1, t}^{D}-R_{t+1, t}^{f}\right)(\%)$ & 19.2098 & 17.7495 & 15.6695 \\
\hline SR & 0.3843 & 0.3264 & 0.1941 \\
\hline Risk-free rate: $E\left(R_{t+1, t}^{f}\right)(\%)$ & 2.2503 & 3.0917 & 4.3834 \\
\hline SD of risk-free rate: $\sigma\left(R_{t+1, t}^{f}\right)(\%)$ & 1.6619 & 1.0823 & 0.5280 \\
\hline \multicolumn{4}{|l|}{ Approximation } \\
\hline$R^{2}$ & 0.9995 & 0.9995 & 0.9997 \\
\hline \multicolumn{4}{|l|}{ Welfare cost } \\
\hline Welfare cost of business cycle (\%) & 9.37 & 9.56 & 3.81 \\
\hline
\end{tabular}

sensitivity analysis. For each risk aversion rate considered earlier, I adjust the composition between active traders and passive equity traders to match the historical risk premium as much as possible, while keeping all other parameters fixed. The results of the second analysis are shown in Table 3.

Panel A of Table 3 reports the results when the risk aversion coefficient is 3 . To match the high historical risk premium, the fractions of active traders and passive equity traders are adjusted to be 3 percent and 47 percent, respectively. The asset pricing results are similar to those in my benchmark economy. The risk premium is high (7.38 percent) and volatile (SD of 19.21 percent), while the risk-free rate is low (2.25 percent) and stable (SD of 1.66 percent). Most importantly, the welfare cost of business cycles increases to 9.37 percent. The higher welfare cost result can be understood as follows: First, active traders are those who respond to the change in state-contingent prices and bear extra aggregate risk. Put simply, they are mar- 
ginal traders who price the risk premium. Second, if these active traders still bear the same amount of aggregate risk as in the benchmark case, then the risk premium will drop since their risk aversion rate is lower now. To maintain the same high risk premium while having a lower risk aversion rate, a larger amount of aggregate risk has to be concentrated and borne by a smaller fraction of active traders. As the fraction of active traders is adjusted from 10 percent to 3 percent, each active trader bears more aggregate risk but is able to enjoy an even higher level of consumption in terms of compensation. The reduction in the fraction of active traders worsens the consumption inequality and, consequently, increases the welfare cost of business cycles.

Panels B and C of Table 3 report the results of the case with $\alpha=2$ and 1, respectively. In both cases, I am unable to match the high risk premium shown in the data even when the fraction of active traders is set to be only 1 percent of the total population. The risk premiums of both cases are significantly smaller: 5.79 percent with $\alpha=2$ and only 3.04 percent with log utility. Nevertheless, the welfare cost of business cycles is even higher, 9.56 percent, when the risk aversion coefficient is 2 . The reason for this is simply that there is a higher inequality in consumption. Although the lower risk premium reduces the inequality of consumption by decreasing the heterogeneity of wealth returns across the population, the smaller fraction of active traders amplifies the consumption inequality even more. The second effect on consumption inequality caused by the diminishing size of active traders dominates the first effect resulting from the lower risk premium. Consequently, the welfare cost increases slightly. The last panel reports the results for the log utility case. The welfare cost drops substantially from 9.56 percent to 3.81 percent when the risk aversion coefficient changes from 2 to 1 . This result is not surprising given that the composition of traders is the same in both Panels B and C.

The second sensitivity analysis demonstrates that the welfare cost of business cycles is even larger with a lower risk aversion coefficient whenever the historical, high risk premium can be matched in my calibration economy. Additionally, for the log utility case, the welfare cost of business cycles is still significant even if my calibration fails to match the risk premium. The welfare cost is 3.81 percent when active traders comprise 1 percent of the total population.

\section{CONCLUSION}

This article demonstrates that heterogeneous trading technologies can play an important role not only in the patterns of asset pricing but also in the welfare cost of business cycles. In my calibrated model, a large amount of aggregate risk is borne by a small fraction of households, while a large fraction of households bear little or even no aggregate risk. The concentration of risk in a limited set of households drives the large risk premium in my model. As a result, sophisticated investors who hold a large fraction of equity in their portfolios are compensated with a much higher return on wealth, while less sophisticated investors earn a lower return on their wealth. A larger wealth return difference worsens the income and consumption inequality. In addition, the new feature of my model-heterogeneous trading technologieshas no distributional effect on consumption in an economy without aggregate shocks because the return difference between stocks and bonds vanishes. Cessation of aggregate shocks can 
greatly improve the consumption inequality caused by the heterogeneity in investment behavior. Therefore, the welfare cost of business cycles is more pronounced in an economy with heterogeneous trading technologies.

For economies with homogeneous trading technologies, the results show an insignificant welfare cost of business cycles. This result implies a large welfare difference between economies with and those without heterogeneous trading technologies, which can be thought of as the welfare cost of investment mistakes made by passive traders. These mistakes include relinquishing high risk premiums and missing the market timing. The significant welfare cost of investment errors highlights the importance of the study of household finance. If a way can be found to avoid these investment mistakes, the average welfare of the society can be improved considerably. Additionally, the results indicate that the welfare improvement from avoiding these investment errors is comparable to that of eliminating business cycles. Therefore, if the elimination of aggregate output volatility is infeasible or extremely expensive, then concentrating more resources on preventing household investment mistakes may be a reasonable alternative. 


\section{NOTES}

1 The SR estimated from the data is enormous and highly countercyclical. My model still falls short of matching the data quantitatively. However, Chien, Cole, and Lustig (2012) extend a similar version of this model by introducing inertia investment behavior among some of the households. Their work shows that the inertia investment behavior helps significantly to explain the large countercyclical variation in the SR.

2 This welfare cost number is significantly larger than those in the standard complete market literature for two reasons. First, the endowment growth shock is assumed to be permanent and hence has an infinite variance, which gives the largest uncertainty for future aggregate consumption. Second, the risk aversion parameter is higher than those in the standard literature.

\section{REFERENCES}

Abel, Andrew B. "Risk Premia and Term Premia in General Equilibrium." Journal of Monetary Economics, February 1999, 43(1), pp. 3-33.

Alvarez, Fernando and Jermann, Urban J. "Quantitative Asset Pricing Implications of Endogenous Solvency Constraints." Review of Financial Studies, Winter 2001, 14(4), pp. 1117-51.

Alvarez, Fernando and Jermann, Urban J. “Using Asset Prices to Measure the Cost of Business Cycles." Journal of Political Economy, December 2004, 112(6), pp. 1223-56.

Bansal, Ravi and Yaron, Amir. "Risks for the Long Run: A Potential Resolution of Asset Pricing Puzzles." Journal of Finance, August 2004, 59(4), pp. 1481-509.

Campbell, John Y. “Household Finance.” Journal of Finance, August 2006, 61(4), pp. 1553-604.

Cecchetti, Stephen G.; Lam, Pok-sang and Mark, Nelson C. "Mean Reversion in Equilibrium Asset Prices." American Economic Review, June 1990, 80(3), pp. 398-418.

Chien, YiLi; Cole, Harold and Lustig, Hanno. “A Multiplier Approach to Understanding the Macro Implications of Household Finance." Review of Economic Studies, 2011, 78(1), pp. 199-234.

Chien, YiLi; Cole, Harold and Lustig, Hanno. "Is the Volatility of the Market Price of Risk Due to Intermittent Portfolio Rebalancing?" American Economic Review, October 2012, 102(6), pp. 2859-96.

Krebs, Tom. "Job Displacement Risk and the Cost of Business Cycles." American Economic Review, June 2007, 97(3), pp. 664-86.

Krueger, Dirk and Perri, Fabrizio. "Does Income Inequality Lead to Consumption Inequality? Evidence and Theory." Review of Economic Studies, 2006, 73(1), pp. 163-93.

Krusell, Per; Mukoyama, Toshihiko; Şahin, Ayşegül and Smith, Anthony A. Jr. "Revisiting the Welfare Effects of Eliminating Business Cycles." Review of Economic Dynamics, July 2009, 12(3), pp. 393-402.

Krusell, Per and Smith, Anthony A. Jr. "Income and Wealth Heterogeneity in the Macroeconomy." Journal of Political Economy, October 1998, 106(5), pp. 867-96.

Krusell, Per and Smith, Anthony A. Jr. "On the Welfare Effects of Eliminating Business Cycles." Review of Economic Dynamics, January 1999, 2(1), pp. 245-72.

Lucas, Robert. Models of Business Cycles. New York: Blackwell, 1987.

Lucas, Robert. "Macroeconomic Priorities." American Economic Review, March 2003, 93(1), pp. 1-14.

Mehra, Rajnish and Prescott, Edward C. "The Equity Premium: A Puzzle." Journal of Monetary Economics, March 1985, 15(2), pp. 145-61.

Mendoza, Enrique G.; Quadrini, Vincenzo and Ríos-Rull, José-Víctor. “Financial Integration, Financial Development, and Global Imbalances." Journal of Political Economy, June 2009, 117(3), pp. 371-416.

Parker, Jonathan A. and Vissing-Jorgensen, Annette. "Who Bears Aggregate Fluctuations and How?" NBER Working Paper No. 14665, National Bureau of Economic Research, January 2009; http://www.nber.org/papers/w14665.pdf. 
Storesletten, Kjetil; Telmer, Chris I. and Yaron, Amir. "The Welfare Cost of Business Cycles Revisited: Finite Life and Cyclical Variation in Idiosyncratic Risk." European Economic Review, June 2001, 45(7), pp. 1311-39.

Storesletten, Kjetil; Telmer, Chris I. and Yaron, Amir. "Cyclical Dynamics of Idiosyncratic Labor Market Risk." Journal of Political Economy, June 2004, 112(3), pp. 695-717.

Storesletten, Kjetil; Telmer, Chris I. and Yaron, Amir. "Asset Pricing with Idiosyncratic Risk and Overlapping Generations." Review of Economic Dynamics, October 2007, 10(4), pp. 519-48. 
